\title{
Measuring And Teaching For Success: Intelligence Versus IQ
}

Robert W. Service, (E-mail: rwservic@samford.edu), Samford University

\begin{abstract}
Optimize action learning and successful evaluation through adopting new views of IQ. $I Q$ as developed here relates to success in life and it is among the most changeable of characteristics. However, IQ as measured in the past is one of the least malleable of factors. Had you rather measure for and teach toward something that is not changeable or something that is very learnable and teachable? If you want to improve success for all in life, forget the normal IQ and begin to use the descriptives you find in this article. The extant literature is replete with theories espousing IQ, EQ, or a combination of both as predictors of success. While the historical importance of IQ as it is currently understood should not be discarded, a more important concept needs to be developed and taught in American educational systems. Simply put, a high IQ does not always correlate with success in life. Yet, our metrics for entry into American universities are principally IQ surrogates. And, our teaching favors those that can remember and pass a test not those that are good at the tasks required by their professions. Academicians need to be more concerned with successful intelligence than traditional IQ for even the most respected of IQ test "fail to do justice to their creators' conceptions of the nature of intelligence (Sternberg, p. 336)." Read on and see if this paper develops a case for changing traditional methods for admission to higher education and teaching toward successful intelligence.
\end{abstract}

\section{Introduction}

W hile the historical importance of IQ as currently understood should not be discarded, a more important concept needs to be developed and taught in American educational systems. Sternberg writes "IQ tests: Measuring IQ not Intelligence (1988: Title of Chapter 2)." We need to address the question, "Is intelligence one thing or many? Clearly, it is many (Sternberg, 1988: p. 72)." Sternberg goes on to say that none of the currently available theories do justice to the full scope of intelligence and perhaps none ever can . . . . whether that theory is explicit or implicit (p. 39). . . . Although many of us act as though intelligence is what intelligence tests measure, few of us believe it (Sternberg, 1985: p. 43).”

Since a high IQ does not always correlate with success in life, it does not seem appropriate that all of our measures to enter any field requiring advanced degrees need to be IQ based. Nor does it seem appropriate that most of our teaching methods favor those that can remember and pass a multiple-choice test over those that are good at the tasks required by a given profession. Academicians need to be more concerned with successful intelligence than traditional IQ for even the most respected of IQ test "fail to do justice to their creators' conceptions of the nature of intelligence (Sternberg, p. 336).”

This paper will develop a case for changing methods of admission to higher education and teaching toward successful intelligence. 


\section{The IQ of Old and How it Relates to A Successful IQ}

[An intellectual is] A man who takes more words than necessary to tell more than he knows (Dwight D. Eisenhower in Dillon-Malone, 2000: p. 162).

Intelligence is well known and is commonly thought of as "mental capacity." However, intelligence is a difficult concept. Most psychologists now agree that intelligence is a highly complex amalgam of a wide range of different sets of knowledge, skills, and abilities which are at best extremely hard to measure and define. Though IQ tests are designed to measure reasoning power, they are not totally indicative of true intelligence. Many feel that IQ tests measure how well someone can adapt to the form of assessment and that is in itself indicative of true intelligence.

You probably know someone who earned all A's, but failed at "life.” Perhaps this explains the colloquial absent-minded professors we all know? In one study, IQs for professors and researchers were reported as 134, 128 for physicians and surgeons, 119 for accountants, and 85 for factory packers and sorters (Howard, 1991: I like this study because I'm a professor!). As we will see later, these scores may have more to do with the test than those being tested! Or they may simply prove that IQ is an excellent measure of how well one will do in America's educational system and on college admissions tests. The "Asian intelligence myth" provides a good example of the impact of IQ and how hard it is to judge. When using grades as a measure of performance, Asian students in American universities perform at a level that indicates their IQs are about 20 points higher. Actually, they are only a couple of point's higher (Pinker, 2002).

Howard Gardner's pioneering book, Frames of Mind (1993), presents his notion of many types of intelligence. Gardner noted seven basic types of intelligence: verbal, mathematical-logical, spatial, kinesthetic, musical, interpersonal, and intra-personal. Gardner's work seems to explain why traditional IQ tests are poor at predicting success in many of life's endeavors such as sales, leadership, management and many other people focused skills.

Perhaps it would be useful here to list the subtest or indexes of items tested for on a normal IQ tests. This is not a primer on testing, because there are plenty of those. The intent is to make the reader relatively aware of what items are covered on IQ tests. Gregory in his 1999 text Foundations of Intellectual Assessment has a very interesting table on "Mean Gains in WAIS-II Subtests, IQs and Index Scores." The table shows in summary form the Subtest/Scale/Index as follows:

- Vocabulary

- Similarities

- Arithmetic

- Digit Span

- Information

- Comprehension

- Letter-Number

- Picture Completion

- Digit Symbol-Coding

- Block Design

- Matrix Reasoning

- Picture Arrangement

- Symbol Search

- Object Assembly

- Verbal Comprehension Index

- Perceptual Organization Index 
- Working Memory Index Processing Speed Index (p. 129).

Though these sub-measures may not be totally meaningful, it is very clear the pattern that is being measured with the Wechsler Adult Intelligence Scale. This test is a standard for measuring intelligence in the "normal" way. It has its efficacy as well as its limitations, many of which have been noted earlier or will be noted shortly.

Guildford in his seminal 1967 work The Nature of Human Intelligence gives 120 measures of intellect presented in a 3 dimensional figure. The five operational dimensions are evaluation, convergent production, divergent production, memory and cognition. The six product factor dimensions are units, classes, relations, systems, transformations, and implications. The four content dimensions are figural, symbolic, semantic, and behavioral factors. This gives 120 measures: 5 X 6 X 4 as represented in Guildford's cube.

IQ is certainly a factor in success in life, especially within organizations related to educational systems, but by no means is it the only factor or the most important. A high IQ can possibly help an interested person learn more about a situation and the people involved in that situation, thus allowing them to become more effective or successful. Or, it could be that because of IQ, someone just coasts along. I have seen both, but more of the latter.

Though IQ is important, it does not take as much intelligence as one might think to succeed. History has shown that people like Ronald Reagan and John Kennedy were great leaders who certainly were intelligent, but by no means were they mental giants. Yet, many other very capable leaders were held back because it was assumed their IQ was too high. Do you suppose that some prospective leaders are so smart they simple don't see the need to build other skills? It is normal to rely too heavily on your strengths and not try to improve your weaknesses. In my Ph.D. quest (which I began at the age of 45), I saw the smartest person never complete the program and one of the least intelligent finish first. As we have all witnessed in many endeavors brains are not enough.

The extant literature is replete with theories espousing IQ, EQ, or a combination of both as predictors of success. Most have found as Drucker said; "There seems to be little correlation between a man's effectiveness and intelligence. . . . Brilliant men are often strikingly ineffectual; they fail to realize that the brilliant insight is not by itself achievement (Cited in Henninger, 2002: p. A16)." None of the major IQ theories fully answer the need to understand IQ as definable, teachable and improvable for success in life's endeavors.

\section{IQ and Other Measures}

Robert J. Sternberg's (1996). Successful Intelligence: How Practical and Creative Intelligence Determine Success in Life starts with a comprehensive description of the traditional methods of measuring intelligence: IQ-testing. He then discusses how measures were developed and what they really mean. Sternberg then discards the importance of traditional IQ and replaces it with successful intelligence which he says is the kind of intelligence that matters in reaching life's important goals.

We must never lose sight of the fact that what really matters most in the world is not inert intelligence but successful intelligence: that balanced combination of analytical, creative, and practical thinking skills. Successful intelligence is not an accident; it can be nurtured and developed in our schools by providing students, even at a very early age, with curricula that will challenge their creative and practical intelligence, not only their analytical skills. It is my contention that successful intelligence should be taught, because it is the kind of intelligence that will be the most valuable and rewarding in the real world after school-both in our work and in 
our personal lives. Our ultimate goal in understanding and increasing our intelligence should be the full realization in our lives of the intellectual potential we all have (p. 269). . . . Those who can recall facts, who may even be able to reason with those facts, don't necessarily know how to use them to make a difference, either to themselves or to anyone else (p. 11).

Conventional tests of intelligence are viewed as measures of only a small part of intelligence, not as measures of most or all of it. They focus on inert academic intelligence and not active successful intelligence. . . . Successful intelligence, as I view it, involves analytical, creative, and practical aspects (p. 47). . . . Intelligence cannot possibly be measured in any large degree solely by the use of multiple-choice tests. Successful intelligence cannot be measured by such tests at all. . . Intelligence is primarily an issue not of amount but balance, of knowing when and how to use analytic, creative, and practical abilities. ... Schools tend to reward abilities that later in life are not very important. . . . Intelligence is partially heritable and partially environmental, but it is extremely difficult to separate the two sources of variation, because they interact in many different ways. ... An important element of intelligence is flexibility. . . . Successfully intelligent people figure out their strengths and their weaknesses, and then find ways to capitalize on their strengths - make the most of what they do well — and to correct for or remedy their weaknessesfind ways around what they don't do well, or make themselves good enough to get by (p. 47-49).

\section{Our Educational Testing and how that relates to IQ}

Sternberg goes on to discuss such standardized tests as the SAT, MCAT, LSAT, GMAT, etc. He says those tests are measuring the same thing that is measured by traditional IQ testing: analytical abilities. "They should be referred to as measuring academic intelligence. Furthermore, the schooling on which they are based is Western schooling, which many children in the world do not receive (p. 68).” In all of these tests he says we seem to place more weight on the predictive measure than on whether a person can actually do a thing or not: like preferring the weather forecast over the weather. In fact, the tests:

May predict people's grades in college with pseudo quantitative precision (p. 35). . . And the perhaps sad fact is that most college admissions officers find high-SAT types to be just the kind of students the professors want: good at memorizing material, competent in academic skills, and savvy in test taking (p. 37).... [Sternberg asks] Why do we pay more attention to predictors than to performance (p. 140)? . . . [He says further that everyone has intellectual strengths that can be developed, but that not everyone has developed them equally.] Yet people have enormous capacity to develop and manifest successful intelligence; how strange that so often we don't let them (p. 45). . . B By thinking to learn, they learn to think (p. 151).

Sternberg writes an interesting analogy about why doctors, lawyers and professors score high on IQ tests. He says it would be like requiring that they all be over 6' tall to get into their respective schools and then after they graduate measuring their height! Yes, they would all be over 6'. Likewise, when you require an IQ measure to get into the school, no wonder the IQ measures of graduates are high.

It is reasonable to use standardized tests as a screen for college admissions. But, most admissions personnel will admit that standardized tests are a forced choice. While they may predict success poorly, most would argue they are better than anything else proposed to date. Colleges and Universities use the standardized tests because they help the institution toward a better use of the very limited resources they have; professors, classrooms, and dorm space. It is wise to accept only students who have increased chances of success. One thing all will agree on is; we miss a many good people with the tests we now use. 
Perhaps these variations of IQ tests used for admissions to the professional schools should be eliminated in favor of direct brainwave testing of intelligence. Zimmer (2004 p. E11) reported: "If neuroimaging grows simultaneously more powerful and less expensive, it stands to become a bigger part of our lives. Neuroscientists are now pinpointing brain regions that are most active in those who score high on intelligence tests. Will we judge the prospects of children someday with a brain scan instead of the SAT?” That's a distinct possibility that is probably more accurate than what we do now. However, Sternberg simply said that our measuring methods and especially our teaching methods are simply wrong headed. I totally agree with Sternberg in this area. Personally, I teach only one thing regardless of the course title. Whether it is in MIS, leadership, strategy, innovation or management, I teach only thinking! I never want to teach just remembering.

Through 40 years of management experience and teaching, I have never encountered or heard any student or manager tell of encountering a management problem that was presented as a multiple choice question that could be answered from a given book! Too often academic problems arrive in ways that do not resemble at all the real life situations one will encounter when they enter a profession. Most academic problems turn up on a silver platter with the answer beneath the napkin used to cover the platter. Not once in over 22 years of practicing managing and leading people at high levels within large organizations did I have to do what was required to make an A on any of my business courses. Does that mean the college courses were irrelevant? Perhaps! After all decisions are choices under varying degrees of uncertainty and if there is no uncertainty there is no decision required. Too often we are not asking for definitional and decision skills, but we are requiring referencing and memory skills. By the time one reaches beyond the freshman year in college, we need to be beyond the memory and reference teaching phases.

In the classroom, give general directions and let the students figure out what is expected. I am known at my University for the general way in which I write the senior project requirements. The instructions read, "Do a project." This leads to multiple questions about form, format, length, media, topic, and outcome assessment. In one particular class meeting, a long question and answer session was finally ended when a student in the front row turned to his classmates and stated loudly, "It's like he wants us to figure it out for ourselves." Amen. "Thus, from our point of view, what students learn in courses is truly only a minor part of the college or any other educational experience (Sternberg, 1996: p. 243).” It is indeed a weak professor that believes students learn the most valuable lessons in their class: they are in denial.

Sternberg went on to identify the following six steps in problem-solving that need to be well understood for development and teaching of successful intellect: 1) Recognition of the problem. 2) Definition of the problem. 3) Formulating a strategy for solving the problem. 4) Proper representation of information-avoiding our preconceived notions; mental sets, frames, models, fixation. 5) Allocation of resources. 6) Monitoring and evaluation. Sternberg writes that the most important step was defining the problem, because if you solve the wrong problem you have done only harm and no good for your real problem. Therefore, when a teacher just asks questions they are not providing students with the most important part of problem solving: formulating the question from too much or too little information.

On the topic of statistics and why the standardized tests are still the norm for admissions into almost all colleges and universities Sternberg said: "I believe that academics and others love statistics because they cover up how poorly things are going at the level of individual cases. When statistical measures account for 10 or even 25 percent of the variation in a group, the level of individual prediction is quite poor (1996: p. 228)." We have got to figure out a way to measure the $75 \%$ versus the $25 \%$ we are currently measuring. Hopefully the changes for the SAT requiring essays will help some in this area. However, I have strong doubts that the essays can be effectively graded. Three reviewers cannot grade over a million essays. The ability to look through bad grammar into the intelligence of the writer is a 
difficult judgmental task. The reviewers should be looking for experience and potential, not merely past academic success or good writing skills.

As an experienced college professor, I admit my limitations in this endeavor. Even after a semester or two of personal interaction with students, it is still very difficult for me to judge intelligence from a written paper. This is a complex issue, but it is certainly an area we must address if we desire to more clearly understand how to teach and test for success. Figure 1 summarizes very briefly what we should do in teaching. Teachers at all levels need to worry more about learning than assessing. Again do you prefer the weather or the weather forecast to see what the weather is doing just now? Notice and you will see a weatherman talking about rain as the sun shines brightly; you want to say, "just look outside!" Do not mimic this behavior.

\section{On to Factors In Successful Intelligence}

Ultimately, Sternberg lists the common characteristics and attributes that are found among successfully intelligent people (the list is an exact quote of his, but after each of the components he gives a long explanation which is not being included here. This material is found in Chapter 8 of his 1996 book).

Successful intelligent people:

1. motivate themselves. ... By letting students lead me, I have entered areas that I never would have explored had I insisted on their doing exactly what I, not they, wanted.

2. learn to control their impulses.

3. know when to persevere.

4. know how to make the most of their abilities.

5. translate thought into action.

6. have a product orientation. . . . they want results. . . . If we demand that students merely "consume" information and feed it back on tests, once again we are depriving them of the kind of learning experience that will be of greatest benefit in the real world, and that is how to use their intelligence.

7. complete tasks and follow through.

8. are initiators.

9. are not afraid to risk failure. ... make mistakes, but not the same mistake twice.

10. don't procrastinate. ... We found that less senior executives had a variety of strategies for fighting procrastination. More senior and more successful executives did not have them, for the simple reason that they had no need for such strategies.

11. accept fair blame.

12. reject self-pity.

13. are independent.

14. seek to surmount personal difficulties.

15. focus and concentrate to achieve their goals.

16. spread themselves neither too thin nor too thick.

17. have the ability to delay gratification.

18. have the ability to see the forest and the trees.

19. have a reasonable level of self-confidence and a belief in their ability to accomplish their goals.

20. balance analytical, creative, and practical thinking.

Some of the definitions of successful intelligence he includes are: 1) The capacity to learn from experience and adapt to your environment; 2) metacognition - that is understanding and control of your own thinking processes; 3) knowing when to use abilities; 4) beyond adaptation including an understanding of when to get out versus adapt; 5) beyond following trends to setting trends. But Sternberg ends by simply saying: "Successfully intelligent people buy low and sell high. They defy the 
crowd and, eventually, come to lead it (1996: p. 189)." "Thus, the true measure of your intelligence is not in a test score; it is in your willingness to develop your own talents (1996: p. 150)." The ongoing crusade of any teaching professional should be to improve the life and success of their students; if that is not the case, they should get out of teaching now.

\section{Why is Successful Intelligence More Important Than IQ?}

Successfully intelligent people are flexible in adapting to the roles they need to fulfill. They recognize that they will have to change the way they work to fit the task and situation at hand, and then they analyze what these changes will have to be and make them (p. 153). . . All of us know people who succeed in school but fail in their careers, or vice versa. They are a constant reminder that there must be more to success than school smarts. . . . Making It in the Real World (Sternberg, 1996: p .220).

It is preferable that you think not of specific IQ, but of overall successful intelligence, which has been defined more clearly in Figure 2. This figure represents a lot of work that cannot be adequately identified in this article, but it will have to do at this point and time (see Service and Arnott's new book being published in 2004). Here we will look only at a few of the principles depicted in Figure 2 for economy of space and to emphasize the point that in teaching you simply must not feel the need to explain every single point. Yes, "leave em hanging if you want em to learn." One of my most successful teaching experiences was when I refused to give a specific answer at the end of a Thursday afternoon class. The next Tuesday the whole class came in in an uproar. They had been thinking and talking about the issue since the prior class: what a joy! If you really understand learning, you realize that we give specific answers to prove how much we know more often than to help others learn. Do not subcome, letting them convince you of what you already know helps them more than your proving what you know.

The definition of IQ depicted in Figure 2 is more directly related to becoming a more effective and successful person. Also, successful intellect is more controllable than traditional IQ. There is a significant amount of IQ in its traditional sense that is required to be successful in many of life's endeavors, but it not that much above average. With large amounts of desire and EQ (see Daniel Goleman's important works of EQ), most can overcome many of the limitations of IQ as it is traditionally measured. Yes, it will be harder to get into institutions of higher learning without a high IQ, but it's not impossible. If you will think about the most successful people you know, I would be confident that many of them did not get into the greatest universities or make the best grades. But they do exhibit an intellect that is often vastly superior to many doctors, lawyers, and professors. The biggest drawback to an average IQ as measured by traditional testing is a person knowing that and allowing it to limit them. The second biggest drawback is the testing that is required to enter institutes of higher learning in the U.S.

There have been a lot of geniuses throughout history who have exhibited superior analytical, multi-variant and inductive thinking that seems to be natural. Since we are talking about IQ - which is a psychological construct - we should mention Sigmund Freud's observations about genius. "In General Introduction to Psychoanalysis, Freud maintained that a genius is a person who longs to attain honor, power, riches, and the love of women, but he lacks the means of achieving these gratifications. So, ... he turns away from reality and transfers all his interest and his libido to the creation of wishes in the life of fantasy, from which the way might readily lead to neurosis (Freud in Wolman, 1985: p. 859).” Freud himself was perhaps the least multi-variant thinker: for him, all problems stem from a lack of sexual fulfillment, and humans are driven by a single desire.

Wolman strongly disagrees with Freud and said: "Creative work is a combination of great abilities combined with superb self-discipline, and mental disorder reduces and may destroy any creative effort (p. 859). Wolman continues on this subject, "Maslow (1970) studied the lives of several prominent 
people, such as Einstein, Beethoven, Lincoln, and others. On the basis of this study, he prepared a list of 15 traits of individuals who reached a high level of self-actualization.

1. The individuals who found self-actualization live very close to reality and judge life in a realistic and accurate manner.

2. Self-actualized individuals accept themselves for whatever they are and, at the same time, they are ready to accept others.

3. Self-actualized individuals display a great deal of spontaneous behavior; although they avoid antisocial or unusual actions, they show a great deal of originality and spontaneity in their thinking and overt behavior.

4. These people are usually devoted to solving a general problem. Their life is perceived as a mission rather than a satisfaction of their own personal needs.

5. Once in a while they have to move away from people in order to contemplate in solitude the problems they are coping with and to develop a more detached viewpoint.

6. They are not conformists. They develop their own ideas, rather independent of the Zeitgeist and cultural influences of their times.

7. The people who found self-actualization appreciate life; although they are not naïve optimists, they love life and they admire its beauty.

8. Some of them can reach beyond observable facts and have a deep feeling of ecstasy going beyond usual human experiences.

9. All of them are very much involved with social problems and display sympathy and compassion for humanity.

10. They develop close personal relations with a small number of friends.

11. Their approach to other people is thoroughly democratic, and they show respect for all other individuals regardless of race, creed, age and so on.

12. They would never choose inappropriate means to reach their goals. They enjoy just as much the road to achievement as they do their final goal.

13. Most of them have a good sense of humor.

14. They are creative and have aesthetic inclinations; they are interested in poetry, science, music and inventions.

15. Throughout their lives they retain intellectual independence and an independent outlook on life (Wolman, 1985: p. 860).”

Although not totally applicable to IQ, these 15 so-called traits help us understand IQ traits of analytical, multi-variant and inductive thinking. It could be argued that Freud used non multi-variant thinking in his statement, while Maslow's 15 traits of exceptional people do exhibit a large amount of analysis and induction. Mackintosh reminds us of the complexity of intelligence, "A further source of temptation here is that we have a single word, 'intelligence' for what we are talking about, as though there were a single thing or unitary trait for that word to refer to (Mackintosh, 1994: p. 8).”

\section{What Can Help You Teach Toward Successful IQ?}

[T]here is little question that unraveling the complexity of environmental influences on IQ will pose a continuing challenge to behavioral science researchers in future years (Bouchard and Segal, 1985: p. 454).

I try to help students, seminar attendees and consulting clients learn to generalize from one situation to another. We all need to be thoughtful and reflective, and be able to use abstracting and reframing, so that we will not have to deal with the same problems over and over. 
The coauthor of our upcoming book mentioned earlier, Dave Arnott, tells this story to make a point that needs to be made here. "The bush pilot shook his head in disgust as he landed his plane on a pristine mountain lake in the backwoods of Alaska to retrieve hunters he had left a week earlier. "I told you last week," he explained, "This Otter style plane will carry the pilot, two hunters with gear, and one elk. I see you've killed two elk and we can't take both of them home.” The hunters pleaded their case, "We hunted at this same camp last year and loaded up two elk on an Otter just like yours." They used their IQ to call on all kinds of data about lift and the power of engines and elevation and the weight of every piece of equipment. The pilot finally agreed, "Your data seems right......let's load up and go home." So, they loaded the pilot, the two hunters with their gear and two elk into the plane. The Otter's huge single engine roared to life and the plane heavily lifted from the water. It struggled over the treetops and banked, headed for a pass in the mountains. They almost made it, but crashed just short of clearing the pass. But, the plane crash-landed smoothly into heavy underbrush, so no one was killed. However, the side of the mountain was a mess of plane parts, hunters gear and dead elk. As the hunters emerged out of the underbrush, one said to the other, "Where in the world are we?" He responded, "I think we're about the same place we crashed last year (Service and Arnott, 2004)!”

The Harvard Case Method is a popular business education technique, because it exposes students to real-life business situations which can be generalized to other situations. The method is effective because students do more than answer questions, they determine what are the questions. For this case method to work individuals must learn to generalize from one situation to another. This generalization requires a lot of thoughtful reflection. When I was at a recent case conference, I got into a heated discussion over providing questions for the students to use when reading a case. "That is how you get them involved," I was told. I simply could not convince most of the participants not to give case questions. Answering predefined questions is nothing at all like real management; it's a total fabrication of reality. One has to learn to develop their own questions to ever succeed in life.

Anyone that wants to learn needs to turn their radios and cell phones off as they drive and think about what they have learned. It would do us all well to do this. Next time you dialogue with anyone just think about what it meant and what you might learn from it. You must learn to learn from everyone in every situation. If you will do this reflection with the goal of seeing if you can reframe the situation to some problem or opportunity you are facing, you'll often find the most innovative and unexpected of solutions. Successfully intelligent people have a habit of reflecting, generalizing, reframing, and abstracting what they have heard, seen and done to the current issues they face.

It's a gross understatement to say that Microsoft founder Bill Gates is very successful. Gates is known for hiring people who are the best at what they do, although many of them are not computer specialists. He does this because he knows that his software must satisfy more than computer geeks. The creativity and Intelligence Quotient of his staff helps Microsoft reach a wide audience of software users.

Vice President Dick Cheney is very smart when it comes to a scenario analysis. Cheney surely thinks about what has happened in the past and puts some level of abstracting to the new situation he faces. However, in at least one situation it appears Chaney's past experience and abstracting actually proved a disadvantage: some would say disaster. His experience had shown that intelligence reports are typically underestimates versus over estimates when it comes to matters such as Iraq having weapons of mass destruction. This "normal" trend caused those getting the estimates to think things were probably worse than reported, simply because that is the norm for intel reports of this nature.

Those of us who must wait for each individual lesson on a platter are destined for a lot of pain and suffering and likely not that much success. The ability to see the relationship of new problems to old problems increases your successful IQ and your ability to solve problems while increasing your IQ. Yes, action beats inaction: but not always! 
Most people seek education for success, yet they seek efficiency not effectiveness. Many people are educated, but few take real advantage of their education. It happens not just in formal education, but also in self and continuing education. One of the strongest determinates of success is the ability to scan the available information and make judgments about what is coming next and where to put your money and efforts. Most successful people have a vast network of information gathering which allows them to see many things others do not. It is mostly because they make an attempt to pay attention to many variables at the same time. The entire discipline of business education springs from economic inequality. Challenge your students with this statement, "If you want to get rich, get out of here and make a difference in someone's life." Scanning many variables to find - and then satisfy - inequalities of supply and demand is very difficult to do. That's because there are many competitors trying to do the same thing.

If you think back to the 2003 Iraqi war you can see that the decision to go to war was made with a lot of interpretation of information. National Security Advisor Condoleezza Rice had a lot to do with the decision. Even if you don't agree with the decision, you probably agree that Condoleezza Rice held among the highest Intelligence Quotients for this particular decision, thus she should be involved in it. We also should be aware that she is highly educated and extremely bright. All of this should allow us to see that a lot of education, intellect, and care went into a very important and possibly history changing decision. Condoleezza Rice exemplifies the education for success and effectiveness that goes along with that. She has been successful in a large part due to her education and ability to process large volumes of information.

When asked how history will treat the decision to invade Iraq, President Bush has responded, "I don't know." It may take years to see, but we do see that America did take action and try something because little else has worked for the past 30 years in the Middle East. The effectiveness of Rice's advice will be judged by history, but we at least know she was highly educated and intelligent and she was well informed. Remember: "Intelligence cannot be well understood without reference to the internal representation of knowledge. . . . External, contextual factors as well as internal, cognitive factors enter into the structure of intelligence, since what may be intelligent in one context may be superseded or become unintelligent in another (Butterworth, 1994:p. 50)." And, "No entity can learn without generating for itself the need to know (Schank and Birnbaum, 1994: p. 84).”

\section{Characteristics That Give Us Problems Related to Traditional IQ: Good and Bad}

Apparently, intelligence and other mental functions are not totally separate entities independent from environmental influences. ... even the best seed will not turn into a plant if it was placed in arid soil. Innate abilities, big and small, may never come to fruition in a destructive environment. The earlier in life the hammer hits, the greater the damage. In some instances the blow can be devastating and the destruction irreversible to both intelligence and mental health (Wolman, 1985: p. 868).

One of the more obvious weaknesses that drags down the Intelligence Quotient is the lack of reading or studying. Very often this is also the type of person that does poorly on standardized tests. When George W. Bush was first mentioned as a presidential candidate, he knew very little about world leaders and geo-political events. This is in part because he was not running for president all of his life as were many other presidents. However, Bush seemed to be a relatively quick study. He was able to overcome the denigrating comments about his alleged low Intelligence Quotient and was quite successful in televised debates with opponent Al Gore.

Once he became President, Bush surrounded himself with brilliant and successful people, not just friends. A quip on the Republican side of the contest goes like this: 
- When George Bush walks into a room he knows he is not the smartest person there.

- When Bill Clinton walks into a room he knows he is the smartest person.

- When $\mathrm{Al}$ Gore walks into a room he thinks he is the smartest person in the room.

I feel much like President Bush when I walk into a classroom of MBA's. I am excited about seeing where the class will lead me and what I will learn.

These analogies should make you aware that gaining a high IQ is obtained by leveraging more than what you have and more than you can reasonably learn. Success in life is about using the diversity and intellect of many others to accomplish more than one person can accomplish alone. None of us is as smart as all of us. Start with reading and studying, but seek the contribution of others and remember to thank them for their input.

Many people don't test well on the standardized tests that are the basis for most advanced educational programs in the U.S. The one thing we can say for sure is that we are missing a lot of capable people by using those tests as the chief criteria for admission to our advanced educational programs. We must realize that those tests are good predictors of who can be successful in passing tests in a given field, but poor predictors of who can be successful in the given profession. Also a high score on a GMAT means you can probably pass the MBA program at most schools but a low score is not nearly as predictive of failure.

I personally improved my GMAT from the $70^{\text {th }}$ percentile to the $93^{\text {rd }}$ percentile from age 28 to age 45. I attribute the improvement to massive amounts of reading. I read only 3 or 4 books before the age of 35. This included textbooks which I did not buy as a undergraduate or MBA because I was not going to read them. Now I read my first 35 year equivalent or more every week: what a joy reading is. In this testing regard think about the following: "Since intelligence changes over the life span (although an individual's ability relative to others may remain relatively invariant), then it follows that the indices used to infer ability necessarily must change (Brody, 1985: p. 355).”

If you want to improve your score on standardized tests or help someone else do it, read more. Some people may need help with test anxiety, but that is rare. If you feel you do need anxiety control help, contact a university and try to find out if they know of a reputable person to help you. Also I have noted time and again the difference between students that have paid attention to and learned from their parents and those that have not. It is simply amazing the difference in those of us that pay attention to most everything and everyone; and those of us that do not pay much attention to anyone or anything! Let's get back to basic intelligence and what it might mean to the few lessons of this somewhat aside paragraph.

"Intelligence can be studied in three ways:

- The adaptation of an organism to its environment

- The complexity of the system of mental structures required by such an adaptation

- The individual know-how, that is the ability of an individual to learn and use those complex structures in an appropriate way, according to the circumstances (Arom, 1994: p. 138).”

These views of intelligence bring to mind the 2000 Presidential election in which Al Gore tried to remake himself many times. Adaptation is a necessity in any battle but it can be a hindrance when people see it as a shallow attempt to become something you are not. Common sense would tell us that people like to see you adapt, but they don't like to think you have no firm foundation upon which your personality, intellect, and principles are based. Learn to learn and concentrate all the time on becoming 
more of what you as a unique individual can become. In teaching and learning all of us should be much more concerned with successful IQ than with traditionally measured IQ.

\section{Teaching for and Measuring Successful Intelligence}

"No one approach to studying intelligence is apt to be "complete" ... A continuing challenge for the future will be the integration of results from various paradigms of research so that our understanding of intelligence will be transparadigmatic rather than specific to the research approach that it happens to use (Sternberg, 1985, p. 110)." You should have gained some knowledge from this article. Some of the ideas were based on science, some on logic, some on experience, and some on supposition, but regardless, the important thing is what you do with the knowledge. It's not IQ or knowledge; it's your application of IQ and knowledge that will determine your success in life.

\section{Accept It and Change It}

What is intelligence? Intelligence is hard to define and descriptions are generally beset with paradoxes. Thus intelligence is attributed to those who have to think because they do not know a lot, and to those who know a lot and so do not have to think (Gregory, 1994: p. 13).

IQ as expressed as successful is among the most changeable things in our lives. However, it is normally measured as one of the least malleable of factors as IQ test of old have shown. Had you rather measure for and teach toward something that is basically not changeable or something that is very learnable and teachable? If you want to improve success for all in life, forget the normal IQ and begin to use the descriptives you find in the Measurement and Improvement Matrix in Figure 2.

Durban, in the fourth edition of his book on Leadership (2004) said about 40,000 books and articles have been written about leadership, yet there is still no one clear definition of leadership. He simply sees it as influence and impact. He does suggest that leadership in a current situation is more often a partnership instead of a dictatorship. This implies to all who aspire to be a modern leader that the old models of command and control may become a thing of the past and we must realize that our followers more often than ever before have the right to say no unless the relationship is mutually beneficial. Perhaps this says that the traditional high IQ is not as important as an IQ that allows one to read others and not use others but to benefit them in a way they want. Maybe the golden rule should now be; "Do onto others as they would have you do unto them.” This requires an IQ that is focused on others, not yourself. As teaching professionals we need to teach for leadership first and foremost. Leadership allows for the most leverage of knowledge and for leading the world out of many of its seemingly endless dilemmas.

Regardless, your goal must be to understand the complexities of real successful IQ and how that relates to your old style measurable IQ; then make IQ meaningful and applicable to you and your situation now and as it will be in the future. Most people die regretting not mistakes, but never trying. Listed below are some principles that are very pertinent to IQ improvement quest (Service and Arnott, 2004; Sternberg, Chapter 8, 1996; and Guilford, 1967 and 1986):

- Desire, attention and focus are foundational to successful IQ.

- The ability to reflect and generalize is critical elements in continually improving IQ.

- Successfully intelligent people learn how to motivate themselves before they worry about motivating others.

- Ability to remain flexible and accept criticism is a requirement of successful IQ.

- People with a high successful IQ let others lead them in many ways, especially about what it takes to motivate others. 
- Memory is important, but not necessarily a detailed memory: just must be able to realize that something you know can be of use and where you can find out more if necessary.

- Ability to pull seemingly unrelated things together as well as to break down complex things into more manageable parts is of great help: this requires attention and practice.

- An Innovative IQ requires first and foremost an inquisitive seeking attitude.

- Successful intelligence is the product of understanding the perspective of others.

- High success IQ requires the motivation to acquire and store information of all types for potential future use.

- Ability to see relationships between things and potential transformations is essential to exhibited successful intelligence.

- Intelligence that pays off is tempered with self-reality and self-control.

- Knowing when to continue and when to cut your losses is key to renewed success.

- In successfully intelligent people the desire to succeed overcomes the fear of failure. Successes and failures really fear the same things.

- Successfully intelligent people have a clear bias for action.

- Making the most of good traits and the least of bad traits is true intellect.

- Action must be the result of thoughts and plans if you are to be successful.

- Procrastination is not the norm for successful people.

- Playing the blame game is out for successful IQ people.

- Self pity is never a part of the independently minded successfully intelligent person.

- Focus and attention are hallmarks of high successful IQ.

- Success requires a certain level of delayed gratification.

- Knowing how much to take on and how much to let go.

- Be a learner not learned.

- Think and think about thinking about thinking and so on.

- Systems thinking; seeing the big picture and the details is a requirement of IQ for success.

- Appropriate self-confidence is IQ.

- Thinking logically, emotionally, practically, creatively, innovatively, and all types of thinking are required to be a continual success.

Add to this list Steven Covey’s (1990) seven habits of highly successful people:

1) Proactivity.

2) Beginning with an end in mind.

3) Putting first things first.

4) Thinking win-win.

5) Seeking first to understand before being understood.

6) Synergize.

7) Continuing self renewal.

There has been a relatively substantial amount of progress on studying the neurological basis for human intellect, but the following statement still basically applies. "Through such emphasis we recognize the evolving nature of research in, and our potential for the eventual understanding of, the neurological basis of intelligence (Hand and Willis, 1985: p. 149).” Following is a wonderful example of the mental effort that has gone on in the literature related to intelligence testing:

It is still valid to assert that intelligence is unitary, incompletely malleable, relatively invariant over the life span, substantially related to socially relevant intellectual achievements, related to the capacity to acquire knowledge in diverse settings, subject to the influences of motivational and temperamental processes that influence both scores on tests and the tendency to actualize one's 
intellectual ability, and subject to cultural influences that change the relationships between the test and the construct (Brody, 1985: p. 384).

In the area of IQ, do you wonder why can't researchers keep it simple? It seems that most research articles on IQ are designed to make a normal person feel stupid. If this article makes you feel anything but encouraged about the ability to improve your IQ, you've missed the main point: you are in control of your own IQ as much as you are your own EQ.

As a final note, I am staying away from group IQ because that is another topic for an article if not several books. This article is talking about a person's own IQ; therefore, group IQ components have no part in personal success.

\section{Conclusion}

If you are lacking in one area don't look for excuses, but think instead about what Penrose said: I feel certain that there is no fundamental difference between mathematical and other kinds of thinking. It is true that many people find it difficult to cope with the abstract type of thinking that is needed for mathematics, whilst finding comparatively little difficulty with the equally convoluted judgments that are involved in day-to-day relationships with other human beings. Some kinds of thinking come easily to certain people, whereas other kinds come more easily to others. But I do not think there is any essential difference - or that there is more difference between mathematical thinking and, say, planning a holiday, than there is between the latter activity and understanding a music-hall joke. Human mathematical intelligence is just one particular form of human intelligence and understanding. It is more extreme than most of these other forms in the abstract, impersonal, and universal nature of the concepts that are involved, and in the rigor of its criteria for establishing truth. But mathematical thinking is in no way removed from other qualities that are important ingredients in our general ability for intelligent comprehension, such as intuition, common-sense judgment, and the appreciation of beauty (1994: p. 107).

Remember these self-evident truths:

- You can’t stop people from thinking - but you can start them.

- Today's preparation determines tomorrow's achievement.

- The only difference between stumbling blocks and stepping stones is the way we use them.

- A mistake is proof that someone was at least trying to accomplish something.

- Two ways to make things better in the minds of the consumers: 1) hype, 2) make real improvements.

- Ideas are funny things. They don’t work unless you do.

As Abraham Lincoln reportedly once said; "A capacity and taste for reading gives access to whatever has already been discovered by others . . ." or as Plato said: "Learning is a matter of remembering what is important." For “There are precious few Einstein's among us. Most brilliance arises from ordinary people working together in extraordinary ways (sources of these quotes are unknown)."

In conclusion, study the dichotomies shown in Figure 1 and figure out how to teach to the right. Study Figure 2 and teach for those principles. Also think about how you might optimize the power of action learning (Marquardt, 2004), not action teaching. Regardless of your viewpoint about IQ, improvements often require what an Army drill Sergeant once said to me: "Sometimes the only way to make the Coke machine work is to give it a good kick." Yes, be enthusiastic, curious, ready, willing, devoted, and honest; but most importantly, kick it into high gear and just do it! 


\section{Figure 1--DICHOTOMIES IN TEACHING}

\begin{tabular}{|c|c|c|}
\hline Many principles you can measure & - versus - & A few principles you can apply \\
\hline Hard quantifiable measurable factors & - versus - & Soft non-quantifiable factors \\
\hline Systems and policies - "things" & - versus- & People skills and concerns \\
\hline Facts and skills & - versus - & Emotional quotient \\
\hline Data & - versus - & Information \\
\hline Knowledge & - versus - & Wisdom \\
\hline Telling & - versus - & Communicating \\
\hline What you want to tell & - versus- & What they need to hear \\
\hline You ask questions & - versus - & They develop questions \\
\hline You teach them & - versus - & They learn \\
\hline You think & - versus - & They think \\
\hline You're responsible & - versus - & They're responsible \\
\hline Taking responsibility & - versus - & Giving responsibility \\
\hline It's the content & - versus - & It's the process and context \\
\hline Helping them stay in the known & - versus - & Moving them into the unknown \\
\hline Power & - versus - & Empowerment \\
\hline Administers and managers & - versus - & Innovates and leads \\
\hline Bottom line & - versus - & Fun and caring \\
\hline Maintain & - versus - & Develop \\
\hline Stability & - versus - & Innovativeness and change \\
\hline Require of them & - versus - & Require of yourself \\
\hline Caution & - versus - & Experimentation and speed \\
\hline They learn & - versus - & We learn \\
\hline What you do with the class & - versus - & What the class does with you \\
\hline I win & - versus - & We win \\
\hline
\end{tabular}


Figure 1--DICHOTOMIES IN TEACHING - continued

\begin{tabular}{|c|c|c|}
\hline Control & - versus - & Trust \\
\hline Autocrat & - versus - & Coach \\
\hline How & - versus - & Why \\
\hline Credit or blame & - versus - & Shared responsibility \\
\hline Information hub & - versus - & Gets problems solved \\
\hline Humor about them & - versus - & Humor about yourself \\
\hline You told them & - versus - & They understood \\
\hline Accept status quo & - versus - & Challenge \\
\hline Surrender to context & - versus - & Master context \\
\hline A good soldier & - versus - & Own person \\
\hline Does things right & - versus - & Does the right things \\
\hline Watches the bottom line & - versus - & Watches the horizon \\
\hline Drives & - versus - & Coaches \\
\hline Authority & - versus - & Goodwill \\
\hline Demands respect & - versus - & Is respected \\
\hline Fear & - versus - & Enthusiasm \\
\hline I & - versus - & We \\
\hline Uses & - versus - & Develops \\
\hline Not enough time & - versus - & Makes time \\
\hline
\end{tabular}


Figure 2: YOUR SUCCESSFUL IQ MEASUREMENT AND IMPROVEMENT MATRIX

STRENGTHS

(enablers-advantages)

WEAKNESSES

(derailers-disadvantages)

STRENGTHS

(enablers-advantages)

WEAKNESSES

(derailers-disadvantages)
Evaluate yourself against the reported traits in this Matrix NATURE (uncontrollable-born) NURTURE (controllable-made)
Q1

_memory \& scholastic abilities

_rationally creative

_quick and bright

__analytical/multi-variant/inductive

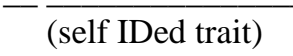

Q2

_thoughtful \& reflective

_ education for success

_wise \& witty

__true thirst for knowledge

(self IDed trait)
Q3

__poor memory and/or vocabulary

_inability to use IQ

_ unprepared and/or nervous

__ gives poor impression of intellect

$-\frac{\text { (self IDed trait) }}{}$

\section{Q4}

_ poor study \& scholastic abilities

_ unfocused \& inattentive

__don't learning from experience

_poor mathematical abilities

(self IDed trait)
Tailor the Matrix below for yourself!

NATURE (uncontrollable-born) NURTURE (controllable-made)

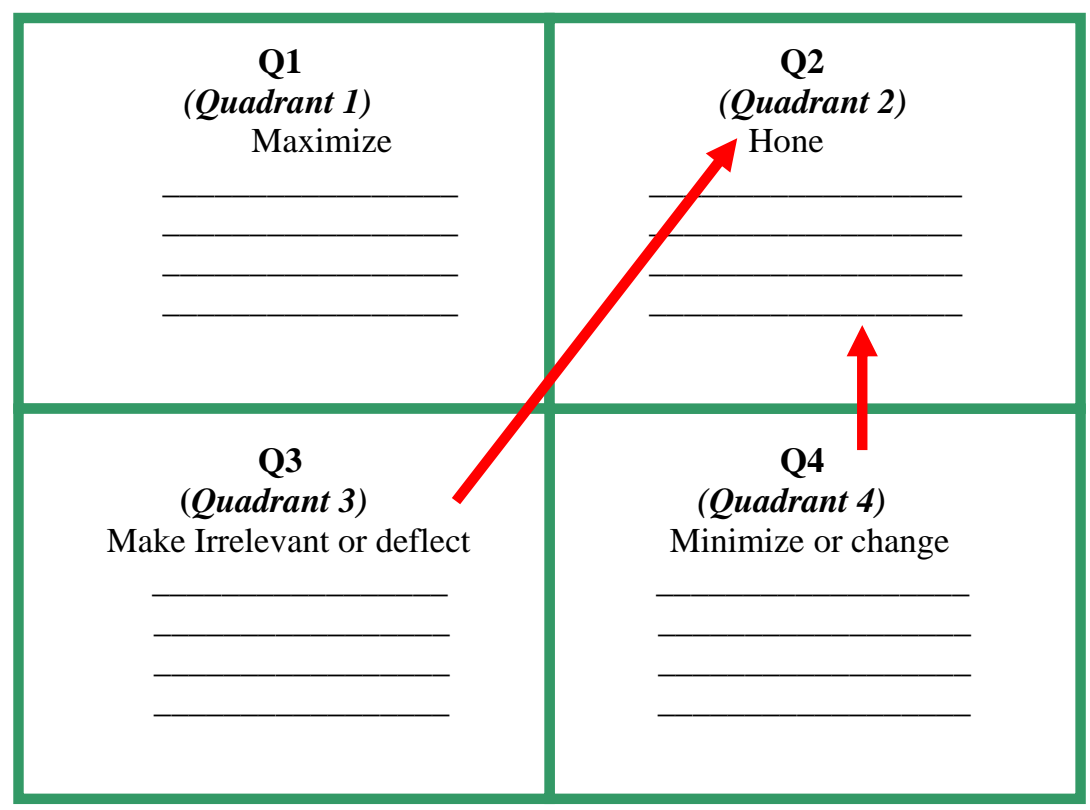




\section{Bibliography}

- Aczel, A. D. (1999). God's Equation: Einstein, Relativity, and the Expanding Universe. New York: MJF.

- $\quad$ Albrecht, K. (2003). The Power of Minds at Work. New York: AMACOM.

- Arom, S. (1994). Intelligence in traditional music. In Khalfa, J. (editor). What is Intelligence? New York: Press Syndicate of the University of Cambridge: pp. 137-160.

- Begley, S. (2004). Self-Esteem Builds on Achievement Not Praise for Slackers. The Wall Street Journal, April 18: p. B1.

- Behe, M. (1998). Intelligent Design Theory as a Tool for Analyzing Biochemical Systems. In Mere Creation: Science, Faith \& Intelligent Design, (Dembski, W. A. Editor). Downers Grove, IL: InterVarsity Press: p. 178.

- Boa, K. D. and Bowman, Jr. R. M. (2002). 20 Compelling Evidences That God Exists. Tulsa, OK: RiverOak.

- Bolles, R. N. (1981). The Three Boxes of Life and How To Get Out of Them. Berkeley, CA: Ten Speed Press.

- Bolles, R. N. (1995). The 1995 What Color Is Your Parachute? (There is a new edition yearly. All editions provide the basic necessities). Berkeley, CA: Ten Speed Press.

- Bosch, L. (2004). Dr. Phil: your total life makeover. Good Housekeeping, March: pp. 119 - 184.

- Bouchard Jr., T. J. and Segal, N. L. (1985). Environment and IQ. In Wolman, B. B. (Editor). Handbook of Intelligence. New York: John Wiley \& Sons: pp. 391-464.

- Bridges, W. (1980). Transitions: Making Sense of Life's Changes. Cambridge, MA: Perseus.

- Brody, N. (1985). The Validity of Tests of Intelligence. In Wolman, B. B. (Editor). Handbook of Intelligence. New York: John Wiley \& Sons: pp. 353-390.

- Butterworth, G. (1994). Infant intelligence. In Khalfa, J. (editor). What is Intelligence? New York: Press Syndicate of the University of Cambridge: pp. 49-71.

- Dauten, D. (2004). What you don't know. The Birmingham News, May 16, Birmingham, AL: p. $1 \mathrm{~L}$.

- Dillon-Malone, A. (2000). The Cynic’s Dictionary. Chicago, IL: Contemporary Books.

- Druskat, V. U. and Wolff, S. B. (2001). Building the Emotional Intelligence of Groups. Harvard Business Review, March: pp. 80-90.

- Frankl, V. E. (1992). Man's Search for Meaning. Boston, MA: Beacon Press.

- Gardner, H. (1993). Frames of Mind. New York: Basic Books.

- Goleman, D. (1995). Emotional Intelligence. New York: Bantam.

- Goleman, D. (2000). Working with Emotional Intelligence. New York: Bantam.

- Gregory, R. J. (1999). Foundations of Intellectual Assessment. Needham Heights, MA: Allyn \& Bacon.

- Grove, N. (1997). National Geographic Atlas of World History. Washington, DC: The Book Division National Geographic Society.

- Guilford, J. P. (1967). The Nature of Human Intelligence. New York: McGraw-Hill.

- Guilford, J. P. (1986). Creative Talents. Buffalo, NY: Bearly Limited.

- Henninger, D. (2002). There must be a real reason for Bush's success. The Wall Street Journal, December 13: p. A16.

- Humphreys, L. G. (1985). General Intelligence: An Integration of Factor, Test, and Simplex Theory. In Wolman, B. B. (Editor). Handbook of Intelligence. New York: John Wiley \& Sons: pp. 201-224.

- Hymowtz, C. (2004. Once a Psychoanalyst, Novartis's Chief Uses His Skills to Manage. Wall Street Journal, June 15: p. B1. 
- Hynd, G. W. and Wills, W. G. (1985). Neurological Foundations of Intelligence. In Wolman, B. B. (Editor). Handbook of Intelligence. New York: John Wiley \& Sons: pp. 119-158.

- Kerlinger, F. N. (1986). Foundations of Behavioral Research. 3rd Ed. Orlando, FL: Holt, Rinehart and Winston.

- Khalfa, J. (editor). (1994). What is Intelligence? New York: Press Syndicate of the University of Cambridge.

- Marquardt, M. J. (2004). Optimizing The Power of Action Learning. Palo Alto, CA: DaviesBlack.

- Mackintosh, N. (1994). Intelligence in evolution. In Khalfa, J. (editor). What is Intelligence? New York: Press Syndicate of the University of Cambridge, pp. 27-48.

- McGrath, J. E., Martin, J., and Kulka, R. A. (1982). Judgment Calls In Research. Beverly Hills, CA: Sage Publications.

- McGraw, P. C. (1999). Life Strategies: Doing What Works Doing What Matters. New York: Hyperion.

- Mintzberg, H., Raisinghani, D., and Theoret, A. (1976). The structure of "unstructured" decision processes. Administrative Science Quarterly, 21(2): pp. 246-275.

- Nohria, N. Joyce, W. and Roberson, B. (2003). What Really Works. Harvard Business Review, July: pp. 42-52.

- Penrose, R. (1994). Mathematical intelligence. In Khalfa, J. (editor). What is Intelligence? New York: Press Syndicate of the University of Cambridge: pp. 107-136.

- Pinker, S. (2002). The Blank Slate: The Modern Denial of Human Nature. New York: Viking.

- Quinn, J. B. (1992). Intelligent Enterprise: A Knowledge and Service Based Paradigm for Industry. New York: The Free Press.

- Sandys, C. and Littman, J. (2003). We Shall Not Fail: The Inspiring Leadership of Winston Churchill. London: Portfolio the Penguin Group.

- Schank R. and Birnbaum, L. (1994). Enhancing intelligence. In Khalfa, J. (editor). What is Intelligence? New York: Press Syndicate of the University of Cambridge: pp. 72-106.

- Shapero, A. (1985). Managing Professional People. New York: The Free Press.

- Sternberg, R. J. (1985). Cognitive Approaches to Intelligence. In Wolman, B. B. (Editor). Handbook of Intelligence. New York: John Wiley \& Sons: pp. 59-118.

- Sternberg, R. J. (1985). Beyond IQ: A Triarchic Theory of Human Intelligence. New York: Cambridge University.

- Sternberg, R. J. (1988). The Triarchic Mind. New York: Viking Penguin.

- Sternberg, R. J. (1996). Successful Intelligence: How Practical and Creative Intelligence Determine Success in Life. New York: Simon \& Schuster.

- Taylor, S. and Gryskiewicz, S. (2003). The Search for Solutions: Choosing the Right Approach to Generating Ideas. Leadership in Action, from the Center for Creative Leadership. Hoboken, NJ: Wiley Periodicals, Inc. January-February, Volume 22(6): pp. 14-18.

- ten Have, S., ten Have, W. and Frans Stevens. (2003). Key Management Models. New York: Portfolio.

- Time Special Issue (2004). The Time 100: The lives and ideas of the world's most influential people. Time, April 26 the entire issue.

- Van de Ven, A. H. (1989). Nothing is quite so practical as a good theory. Academy of Management Review, 14(4): pp. 486-489.

- Van de Ven, A. H., Angle, H., and Poole, M. S. (Editors). (1989). Research On The Management of Innovation, Volumes 1 and 11, Cambridge, MA: Ballinger.

- Vandenberg, S. G. and Vogler, G. P. (1985). Genetic Determinates of Intelligence. In Wolman, B. B. (Editor). Handbook of Intelligence. New York: John Wiley \& Sons: pp. 3-58. 
- Vroman, H. W. 1995. Innovation in Professional Education: Steps on a Journey from Teaching to Learning. San Francisco: Jossey-Bass.

- Vroom, V. H. and Jago, A. G. (1988). The New Leadership: Managing Participation in Organizations. Englewood Cliffs, NJ: Prentice Hall.

- Wolman, B. B. (Editor). (1985). Handbook of Intelligence. New York: John Wiley \& Sons.

- Wolman, B. B. (1985). Intelligence and Mental Health. In Wolman, B. B. (Editor). Handbook of Intelligence. New York: John Wiley \& Sons: pp. 849-872.

- Woodward, B. (2004). Plan of Attack. New York: Simon \& Schuster.

- Wysocki, B., Jr. (2003). Lobes of Steel: Giving Your Memory a Workout. The Wall Street Journal,_April 29, pp. D1 and D8.

- Yasuda, Y. (1991). 40 Years 20 Million Ideas: The Toyota Suggestion System._Cambridge, MA: ProductiveityPress.

- $\quad$ Zadek, S. (2001). The Civil Corporation: The New Economy of Corporate Citizenship. Sterling, VA: Earthscan.

- $\quad$ Zaleznik, (1989). The Managerial Mystique: Restoring Leadership in Business. New York: Harpers \& Row.

- Zimmer, C. (2003). Peering Into the Brain. Newsweek, June 9: pp. E10-E11.

\section{Notes}

